Citation: Rowsell, J., \& Wohlwend, K. E. (2016). Free play or tight spaces? Mapping participatory

literacies in apps. The Reading Teacher, 70(2), 197-205. doi:10.1002/trtr.1490

\title{
Free Play or Tight Spaces? Mapping Participatory Literacies in Apps
}

\author{
Jennifer Rowsell, Brock University \\ Karen Wohlwend, Indiana University
}

\begin{abstract}
Building on existing research applying app maps (Heins-Israelson, 2015), the authors take ideological orientation to broaden app evaluations and consider participatory literacies, social and communicational practices relevant to children's everyday digitally-mediated lives . Drawing from their North American elementary classroom studies on children's technology play with iPads, the authors compare four typical literacy practices with apps: practicing a skill, reading an e-book, animating a film, and designing an interactive world. A rubric and radar maps are introduced to help teachers assess and visualize educational apps' potential to develop six dimensions of participatory literacies: multiplayer, productive, multimodal, multilinear, pleasurable, and connected.
\end{abstract}

\section{Teaser Text}

What kinds of literacy practices are children really using when they play with educational apps? The article presents a framework to help teachers evaluate an app's potential for developing the literacy practices needed to fully participate in digital cultures.

\section{Introduction}

Since 2009 when Apple launched the slogan "There's an app for that", an app blizzard has blanketed the digital landscape. There are apps - software applications for smartphones and tablets - for walking, talking, shopping, cooking, driving...it is hard to think of an everyday interaction that is not mediated by an app in some way. Many involve digital literacy practices with print: posting on social media, texting friends, and reading webpages. However, apps also require new "printless literacies" that continually change with each round of updates: pressing to open a screen, swiping right to accept or left to reject, sharing videos, skipping ads, and so on.

Mobile devices are pervasive, accessible, user-friendly, and just the right size for little fingers. So it's not surprising that as more parents "passback" their phones to their children (Shuler, 2010), more children are playing, viewing, reading, posting, sharing, and learning with apps. Over $75 \%$ of children under nine have access to some kind of mobile device and its apps (Rideout, 2013). An analysis of the best-selling apps on Apple's App Store showed that $60 \%$ of the top 25 apps targeted very young children (Shuler, 2012). Clearly at home, many children are using apps designed and marketed as "educational”. But an "app gap" (Rideout, 2011, p. 21) describes persistent inequitable opportunities to use mobile technology, contrasting U.S. children in higher-income families who have cutting-edge software, 24/7 robust broadband networks, and personal mobile devices with children in lower-income families who may not know "what an 'app' is" (Rideout, 2011, p. 21). Although numbers on mobile ownership have 
increased in the last five years (Hirsch-Pasek, Zosh, Golinkoff, Gray, Robb, \& Kaufman, 2015), significant disparity remains in the quality of children's digital experiences. In a survey of 1,463 U.S. families, 35\% of lower-income parents reported downloading educational apps for their child compared to $75 \%$ of higher-income parents (Rideout, 2013).

With all of this consumption, it is difficult to sort high-quality from low-quality apps. Recently, researchers have devised rubrics to discriminate between higher and lower quality apps (Heins-Israelson, 2015; Hirsch-Pasek, et al., 2015) that were helpful as we developed the app maps in this article. One rubric matches literacy skills (e.g., concepts about print, word recognition, or language development) with features that apps need to have to align with a given skill or competency (e.g., e-books, multimodal composing, or, mind-mapping). Based on the SAMR Model (Puentedura, 2010), Heins-Israelson developed this rubric to evaluate the effectiveness of apps by mapping disciplinary characteristics of early literacy teaching and learning and the affordances necessary to think through the app. The disciplinary characteristics and affordances are: 1 ) the multimodal strength of the app; 2) the literacy content it exhibits; 3) Intuitiveness of the app's design; and, 4) the degree of interactivity. Drawing on Heins-Israelson's categories and rubric, we extend this work by focusing on the need to think critically, looking beyond the app's content and ease of operation skill-based or autonomous (Street, 1984) to understand the impact on children's opportunities to develop the skills and dispositions as producers rather than consumers. In short, we take an ideological view of literacy development with apps in making a rubric based on participatory literacies. Rather than an autonomous focus on mastery of literacy practices such as phonemic awareness, word recognition, and vocabulary or competencies in operating technologies, we orient our evaluation of apps and corresponding rubric toward everyday literacy (Rowsell \& Pahl, 2015) that recognizes children's lived experiences make them active participants in daily apprenticeships in digital culture, social media and architectures of participation, media interests, modal diversity, local-global sensibilities, emotions, embodiment, and identity investment. As researchers who approach literacy education from an ethnographic and multimodal perspective, we have situated our research in a variety of contexts by accounting for the role of context while at the same time acknowledging that literacy always involves more than one mode to make meaning. In designing the rubric, we thought seriously about a child's whole experience, beyond school hours, to recognize literacy development as nested within different contexts (e.g., home, community, school, etc.) and as involving a variety of communicative systems (e.g., words, visuals, interactive texts). This way of thinking about context, practices used, and the identity of the learner has been called an ideological approach to literacy (Street, 1984). From this perspective, a evaluation of apps based on the conventional, discrete literacy skills highly valued in school misses the learning potential of more open, multimodal, connected nature of apps.

In this article, we identify six dimensions of ideological participatory literacies that influence children's interactions with apps, creating a rubric based on our fieldwork observations of children's play in school and after-school learning contexts. We illustrate the participatory literacies rubric with radar graphs to visualize and compare apps according to the ways learners actually use them. 


\section{Apps and Participatory Literacies}

Participatory literacies are ways of interpreting, making, and sharing digital multimedia (e.g., games, video, images, animation) to connect with digital cultures. Learning to belong and how to contribute within participatory cultures requires understanding the social practices or the ways things are done in this place. Participatory literacies produce interactive and improvised interactions with screens, created moment-to-moment from voice, image, and action, in paths much messier than the lines of print in books that progress left-to-right, top-tobottom, and from beginning-to-end in a story in a classroom writing workshop. In participatory cultures, players play toward shared goals, form alliances and social relationships, and project selves across networks as they inhabit avatar characters in virtual worlds (Black, Korobkova, \& Epler, 2013; Wohlwend, Vander Zanden, Husbye, \& Kuby, 2011) and videogames (Gee, 2005).

\section{Multiplayer}

Appreciating the multiplayer dimension requires looking beyond an individual player's interactions with game elements such as characters, narrative, and strategies. Instead, apps should encourage a group of players to negotiate over the next moves, meanings, or turntaking and to cooperate and communicate as they move the play forward. In this way, participatory literacies are co-constructed, in conversation or play with others. For example, videogame play merges each individual player's moves into a joint production, whether a coordinated sequence of moves and counter-moves or a simultaneous orchestration of each players' performance (Gee, 2007).

\section{Productive}

The productive dimension reflects whether and how well an app supports a user's creation of content, such as digitally painting, photographing, filming, or composing an original or remixed text. Some apps that allow content creation limit children to selecting pre-set stamps, snippets of talk, or moves. Participatory literacies are productive so that children should not simply consume commercially-produced content. To develop critical understanding of commercial app producers' motives, children need opportunities to produce and share their own media as they learn to contribute as full participants in digital cultures (Buckingham, 2003; Burnett \& Merchant, 2014; Marsh, 2012). There is a natural productivity that happens when an individual plays an app where they can navigate, represent and construct objects, buildings, or even explore storied worlds. For example, in videogame worlds where players build structures and think about design and aesthetic histories, they can construct a particular kind of building like an art deco building, which involves researching the art deco era, fundamentals of architecture, and historical events that happen during this period in history. These practices and this kind of thinking are qualitatively different from pre-set stamps on designs or working within the confines and rigidity of templates and pre-determined plotlines.

\section{Multimodal}

The multimodal dimension of apps gives players the feeling of being immersed in another world through sensory aspects such as sound, image, and movement in images, liveaction video, or animation. Image and animation are now a dominant means of communication 
in digital networks and so contemporary texts work on new logics of design (Kress, 2004, 2010) that govern how modes of expression and communication mean. Apps that engage more senses have higher modal complexity and therefore offer more potential for meaningful, relevant, and participatory engagement. For example, multimodality enables very young children to playfullly use action and image to convey their ideas (Rowe, 2010) while older youth assert agency through layered literacies, as they move among various modalities and practices that are not specifically related to gaming but that are available within a videogame space (Abrams, 2015). Apps open or constrain meanings and participation as players make choices based on multimodal affordances, that is, their selections are shaped by whatever mode best or most aptly suits their designs and whichever set of practices best fits their purposes (Kress, 1997). Multimodal logics are readily apparent when playing an app or observing someone play an app. For example spatial games naturally invite visual modes and embodied practices with gaze, posture, and image such as leaning in, angling your body, and tapping vigorously.

\section{Open-Ended}

Open-ended apps allow players the freedom to journey, or move into different storylines and varied texts and genres during game play. Journeying with an open-ended goal avoids a narrowing, reductionist, schooling model and provides room for personalizing play, moving across other texts during play, and collaboratively composing a text with others. Where a player starts and where a player ends up can be quite different and this open-ended quality to apps aligns with authentic and idiosyncratic experiences of play. Beavis (2013) calls attention to a relationship among the dimensions of design and the dimensions of play, alluding to this open-ended quality of games that "do not fit readily either into available definitions of literacy or into subject-specific parameters within school" (p. 72). Flewitt, Messer, and Kucirkova (2015) described a study that they conducted in early years settings where children played an app called Our Story. The authors commented on the flexibility and responsiveness of the media and children relished in the openness of the app. From this openness came independence and concentration because tasks were not limited to one or two actions, but to a panoply of actions, texts, and participatory moments. Keeping apps open allows for a DIY quality where players can follow the tide of game play while not quite sure where they will end up (Buchholz, 2015).

\section{Pleasurable}

App ratings and frameworks tend to privilege learning, thinking, and participatory dimensions at the expense of affective, embodied, and feelingful dimensions. However, when a gamer is immersed in an app, passion is palpable and has prompted researchers to think about what apps do for people when they revel in play. Marsh (2011) has for many years conducted ethnographic research in homes documenting the expansive and sophisticated nature of media play that children engage in online and offline when they consume different media. In her extensive mapping of media consumption practices and patterns, Marsh shows the passion and power that global media networks like Disney have over children. As for embodiment and pleasure, Leander and Boldt (2013) give a bird's eye view of the spirited consumptive movements and patterns as 10 -year-old Lee moves from a videogame to physical play to 
vernacular texts with his friend over the course of an afternoon. The article captures how nascent our understandings are about embodied meaning making and how far we need to go in literacy studies (Rowsell \& Pahl, 2015). Drawing on ethnographic inquiries in informal learning environments, Thiel (2015) identifies 'muchness' and passion prominently on display in a group of young children when they improvise with materials made available to them during their after-school program. Pleasure is individual, making it difficult to predict and preplan. However, we can evaluate an app's pleasurable dimension by looking at the depth or 'muchness' of children's engagement, whether they choose to stay or return to play again, and whether there are opportunities for children to connect to their passions, and to get lost in the moment and immersed in playful creativity.

\section{Connected}

Apps have connectivity if they link users to digital resources and sharing on social networks. Participatory literacies are rooted in notions of connected learning where users not only link and navigate websites but also learn to participate in online cultures on vast digital networks that host affinity groups (Gee, 2003), fan communities or social media such as Facebook or Twitter. These connections are expected to be reciprocal - members expect that when they post content to these sites, others will respond, comment, like, or follow. A participatory culture is a culture with relatively low barriers to artistic expression and civic engagement, strong support for creating and sharing one's creations, and some type of informal mentorship whereby what is known by the most experienced is passed along to novices. A participatory culture is one in which members believe their contributions matter, and feel a degree of social connection with one another (at the least they care what other people think about what they have created) (Jenkins, Purushotma, Clinton, Robison, \& Weigel, 2006, p. 3).

\section{Illustrative Examples in Classroom Contexts}

To illustrate how the six dimensions in the rubric influence children's interactions with apps, we draw from our fieldwork in schools and formal and informal learning contexts to compare apps according to the ways learners actually use them. In this section, we present four common practices that we've observed children using with apps: 1) practicing a skill, 2) reading an e-book, 3) animating a video, and 4) designing an interactive world. This list is not meant to be comprehensive but to offer a sampling of the most frequent literacy practices we observed in children's use of educational apps. Examples are drawn from our video data in K-6 classrooms (Wohlwend, 2015) and from fieldnotes written by undergraduate teacher education university students who worked one-on-one with elementary schoolchildren as they explored apps (Rowsell, Maues, \& Colquhoun, forthcoming). The university tutors selected apps that they thought would appeal to their student and that would develop some aspect of participatory literacies, sometimes soliciting suggestions from the children. Drawing from our fieldnotes and our own review of the apps, we analyzed each app's features using the rubric in Table 1 to see how well the app encouraged development of the six dimensions of participatory literacies.

Table 1: App Map Rubric: Six Dimensions of Participatory Literacies 


\begin{tabular}{|c|c|c|c|}
\hline & 4 & 2 to 3 & 1 \\
\hline & High & Medium & Low \\
\hline Multiplayer & $\begin{array}{l}\text { Accommodates } \\
3 \text { or more players }\end{array}$ & $\begin{array}{l}\text { Accommodates } \\
2 \text { players }\end{array}$ & $\begin{array}{l}\text { Accommodates } \\
1 \text { player }\end{array}$ \\
\hline Productive & $\begin{array}{l}\text { Enables creative actions } \\
\text { or content additions } \\
\text { rather than pre-set } \\
\text { components (e.g., make } \\
\text { or import own content) }\end{array}$ & $\begin{array}{l}\text { Enables some original } \\
\text { content; choices among } \\
\text { pre-set images or texts } \\
\text { (e.g., range of avatar } \\
\text { clothing and features, } \\
\text { original story action) }\end{array}$ & $\begin{array}{l}\text { Limited original content, } \\
\text { pre-set personalization } \\
\text { element (e.g., insert } 1 \\
\text { element to personalize; } \\
\text { minimal choices for } \\
\text { avatar design) }\end{array}$ \\
\hline Multimodal & $\begin{array}{l}\text { Enhances meaning } \\
\text { through combinations of } \\
4 \text { or more modes: music, } \\
\text { image, sound effects, } \\
\text { animation; inspires play } \\
\text { with real world materials }\end{array}$ & $\begin{array}{l}\text { Enables manipulation } \\
\text { and combinations of } \\
\text { several modes: image, } \\
\text { paint, movement } \\
\text { (animation), speech, } \\
\text { music }\end{array}$ & $\begin{array}{l}\text { Primarily print word } \\
\text { processing tools, } \\
\text { supplemented with } \\
\text { stamping or basic paint } \\
\text { tools }\end{array}$ \\
\hline Open-ended & $\begin{array}{l}\text { Open-ended storytelling } \\
\text { with many tangents } \\
\text { (e.g., hypertext, portals } \\
\text { as in videogames) }\end{array}$ & $\begin{array}{l}\text { Enables an alternate } \\
\text { ending or multiple paths } \\
\text { to complete a task; } \\
\text { supports revisions to } \\
\text { insert additional events }\end{array}$ & $\begin{array}{l}\text { Enables a single storyline } \\
\text { in an unvarying } \\
\text { sequence that proceeds } \\
\text { from beginning to end }\end{array}$ \\
\hline Pleasurable & $\begin{array}{l}\text { Players choose the app } \\
\text { voluntarily and stick with } \\
\text { it; return and play again; } \\
\text { talk about the app } \\
\text { before or after playing }\end{array}$ & $\begin{array}{l}\text { Players play the app } \\
\text { once and appear to } \\
\text { enjoy it }\end{array}$ & $\begin{array}{l}\text { Players play app when } \\
\text { assigned or to meet } \\
\text { school expectation }\end{array}$ \\
\hline Connected & $\begin{array}{l}\text { Saving and facilitated } \\
\text { sharing on videosharing } \\
\text { sites (e.g., youtube) }\end{array}$ & $\begin{array}{l}\text { Opportunities to export } \\
\text { app artifacts for saving } \\
\text { and external emailing or } \\
\text { posting }\end{array}$ & $\begin{array}{l}\text { Internal network sharing } \\
\text { only or proprietary } \\
\text { formats that require } \\
\text { website registration to } \\
\text { view }\end{array}$ \\
\hline
\end{tabular}

For each of the following apps, we rated the app with the rubric and entered the scores into a spreadsheet to generate a radar chart that puts the six dimensions in relation to one another. (For more on radar charts, see Wohlwend, 2012).

\section{Practicing a Skill}

Skills practice that features simple games to practice isolated skills is a leading genre in educational apps (Hirsch-Pasek, et al., 2015). SpellingCity, typical of this genre, enables practice of spelling and word study skills through a series of interactive games. Players select a word list to practice and engage in a range of vocabulary and phonics tasks. The app has a list of clickable items such as unscrambling words, spelling test, hangmouse (a version of hangman), missing 
letters, alphabetize, and word match with a clear goal of playing interactive matching and sorting games to focus on word study skills. Within the tutoring environment, tutors used the app as a segue into reading and writing activities.

When we analyzed children's literacy practices with this app using the rubric, some multimodality was apparent through the user interaction through touch and gesture with words, icons, and images on the screen. Although there may be pleasure in the gratification of spelling words correctly and these games seem 'fun' when compared to other school tasks, children were not apt to choose this app as a recess pastime. As the app map below displays (Figure 1), skills practice apps offer minimal opportunities for multiplayer, productive, connected, multilinear, and open-ended dimensions.

Figure 1: Practicing a Skill: SpellingCity

\section{SpellingCity App Map}

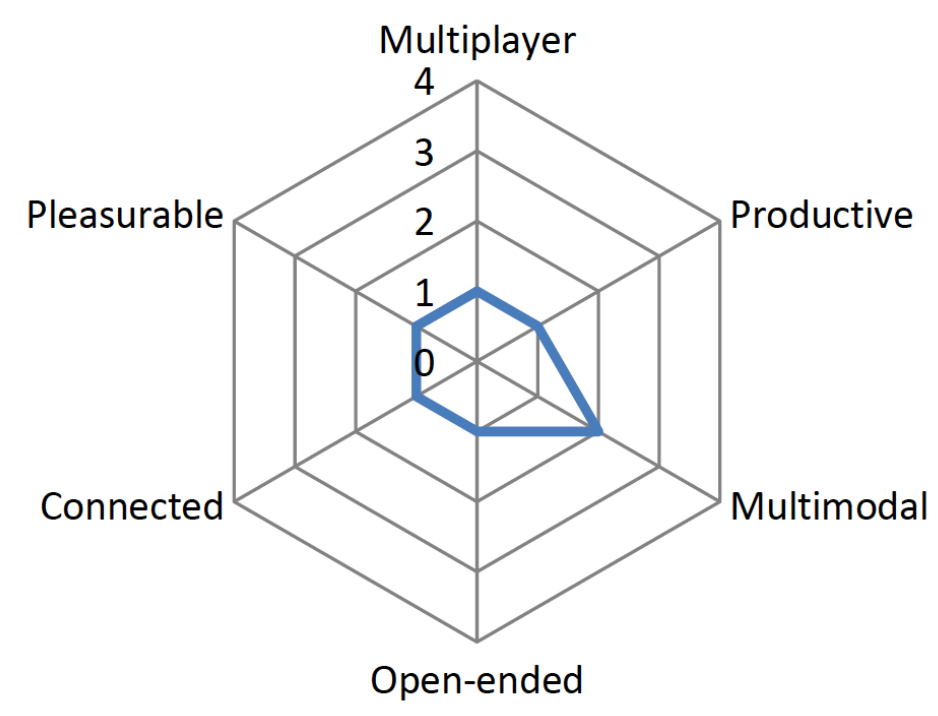

\section{Reading an E-Book}

E-books make up another large genre of educational apps, offering readers animation, video, sound effects, and other interactive features that bring books to life. Like print books, readers' movement through e-book text is influenced by genre: fictional stories are linear and move from beginning to end, non-fiction texts are hierarchical, with sub-topics that offer tangents to delve more deeply into material. E-book apps can be highly multimodal such as the Sound Uncovered app by San Francisco Exploratorium-- an "interactive book featuring auditory illusions, acoustic phenomena, and things that bump, beep boom and vroom" (Apple Inc., 2015). E-book apps that focus on reading offer limited potential for users to produce new content but provide pleasurable and multimodal extension that deeply engages children who have a passion for specific topics (see Figure 2). 
Figure 2: Reading an e-Book: Sound Uncovered

\section{Sound Uncovered App Map}

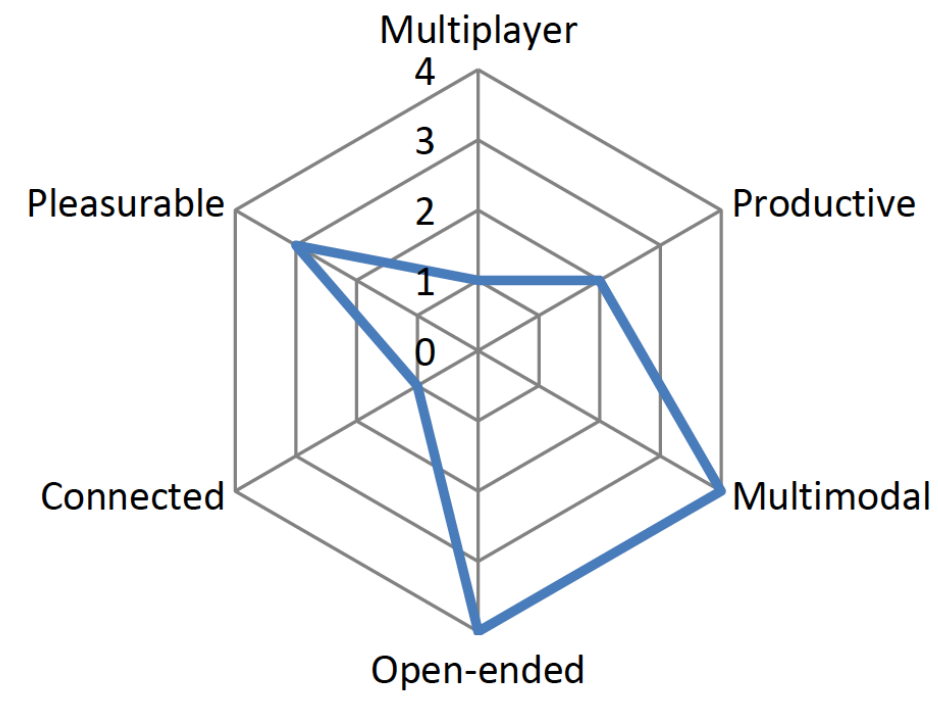

\section{Animating a Video}

The onset of touchscreens and icon-based tools have made it possible for children to use apps to independently create and edit their own animated videos. Toontastic, a leading app in the digital animation genre, offers stock cartoon character sets and scenes that suggest simple storylines (e.g., fairy tales, pirate attacks, space adventures) that follow a pre-set linear narrative sequence of scenes, from introduction to climax and conclusion. A blank canvas and paint palette allows users to create their own additional characters and backdrops while editing tools enable overlays of music or sound effects. The ability to add and animate numerous characters through simple finger swipes and taps makes it possible for multiple players to easily collaborate on a single story, although too many fingers on the screen sometimes caused the app to crash. In the Toontastic App Map below (Figure 3), the app scores higher in multimodal and productive dimensions but lower on connectivity due to its limited possibilities for videosharing on the in-app Toontube network. 


\section{Toontastic App Map}

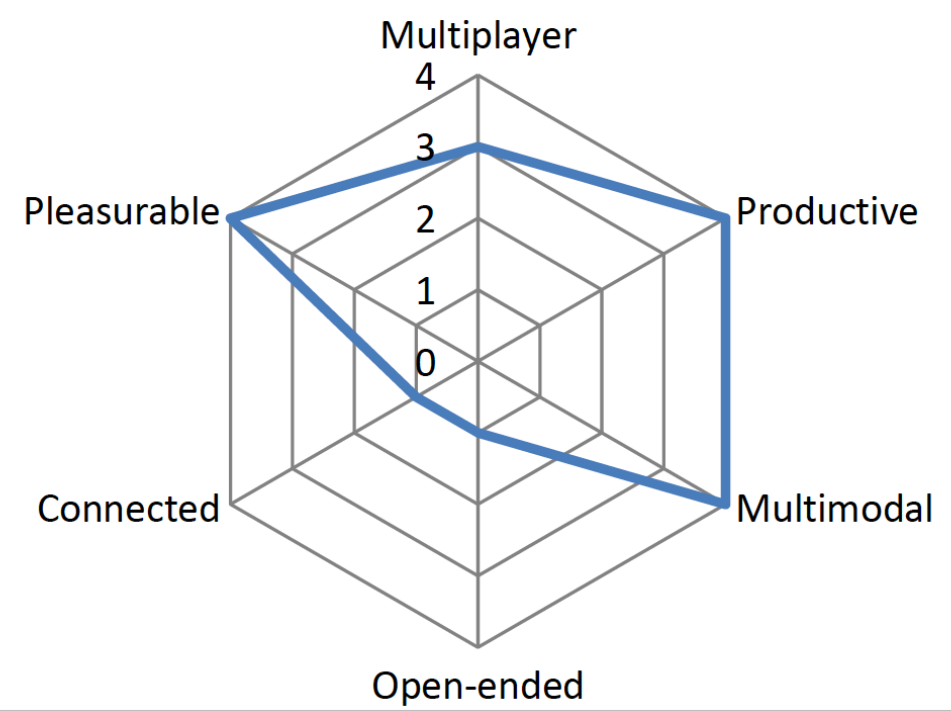

\section{Designing an Interactive World}

The most complex apps allow children to design spaces or games for others to engage, requiring children to take a designer's perspective for an imagined future player, much like a writer imagines a future reader. The exemplar of this genre is Minecraft, an open world and/or survival game where players build and move through a world of cubes, breaking up cubes as they work their way through the landscape. In survival mode, players gather resources to kill monsters and to mine minerals and use tools for the main purpose of protection. In creative mode, players use an unlimited number of blocks and tools to create and build constructions as they design worlds. In all modes, players can build things such as houses, towers and landscapes.

What became clear to us is that there is more to app design and use than meets the eye and that apps often lead to productive sensibilities and dispositions where a player follows the tide of ideas and curates different kinds of information. Our observation showed that children's play in Minecraft led them into not only the immersive, design-laden world of the in-app world, but also onto websites to learn how to make swords, the properties of Medieval life, or varying forms of energy. For some this might seem like a dizzying trip through digital contexts, but for children passionate about the game, it is a thinking process that feeds into design and productive work. In this way, Minecraft is an expansive app that covers all of the dimensions because it is multimodal, multiplayer, open-ended, connected, embodied, invites passion for design and for survival and it can be highly productive as players design and create their own landscape (see Figure 4). 
Figure 4: Designing an Interactive World: Minecraft

\section{Minecraft App Map}

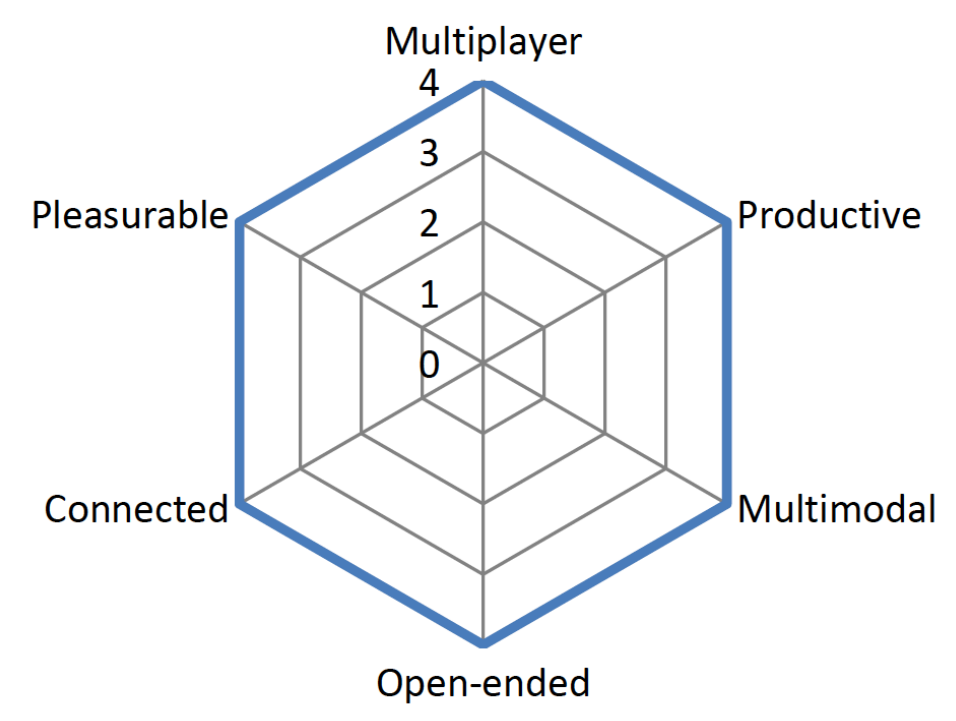

Expansive or Restrictive Apps as Ideological Literacies

Participatory literacies can be analyzed through tighter or looser framings of literacy (Rowsell \& Pahl, 2015). A tighter framing of literacy tends to focus on schooling competencies, hierarchical structures of knowledge that heavily draw from the disciplines of psychology and cognitive science. Although this work has pushed the field to be more rigorous and to quantify success, such framing is almost entirely based on words in print-based texts. In contrast, a looser framing of literacy considers contexts, more open and unbounded structures of knowledge that draw heavily from the disciplines of anthropology, sociolinguistics, the humanities and social sciences. We argue that contemporary participatory literacies demand looser framings of literacy so that they align with the logic and design of the apps children experience in everyday life. Apps do not function solely on a print-based logic and design, they are participatory, multimodal, open-ended and connected.

Situating an ideological model of literacy, based on his fieldwork in Iran, Street used the term ideological to signal the importance of contexts where literacy happens as shaping understanding; or as Bloome and Green define it, "an ideological model is defined as situated, shared cultural frameworks and models that inform when, where, and how written language should be used ... as well as how written language means within and across social situations (Bloome \& Green, 2015). We would argue that a contemporary view of ideological literacy relies on far more than written language - it calls on at least two or modes to communicate and express ideas, it is multimodal.

To illustrate an ideological approach to apps, we draw from on-going research with children and adolescents as they play apps as a part of an after-school tutoring program. In this instance, we focus on Calvin whom we feature below who is a grade eight student who struggles with his literacy skills at school. The tutor, Peter, frequently describes how Calvin 
learns best when a lesson has a visual focus with other supplementary or supporting modes to express meanings. Here is an excerpt from Clare's fieldnotes:

Peter saw the app Idioms, and asked me what they were. I gave him the example of Achilles' Heel, and since he seemed interested, he browsed that app for a couple minutes. The app provides an illustration of certain idioms. It's not a super engaging app, so we didn't spend long on it. Finally, we ended off the session by exploring more mythology. One app called Mythology lets you read snippets about various gods from all different types of mythology. Since this app is fairly dull, with only text, Peter did not spend long on this one. He did enjoy the Gods of Egypt app, which gave an illustration of the god and a little blurb of information. Peter often told me about the various gods before we even read about them! He is very good at remembering what he has read and making connections between the gods. April 8, 2015

Peter is an eleven-year-old language learner from Brazil who has been living in Canada for only six months. Peter is an avid reader and his English proficiency is strong and he is fluent in Portugese. After working with him for a few weeks, during our interview with Clare, she shared how Peter has a passion for history and he is drawn to apps on history. Observing Peter, he tends to listen to TED talks and he tries out a variety of apps and knows immediately which ones are informative and engaging and which ones are not. With the example above, the app that Clare calls 'Mythology' has different topics such as Greco-Roman Gods, Norse Mythology, and World Mythology and it has some podcasts, but it is primarily printed words with accompanying pictures. There is a bit more interactivity with the Gods of Egypt app, but what Peter liked most are the detailed visuals with touchable features about gods like Isis, Hapi, Horus, Ma'at and he admires how expansive and open-ended the app is. An ideological approach to teaching Peter with iPads would invite discussions about history and about Brazilian culture in a style that draws out his autodidact tendencies and accesses his cultural background. On his own, Peter will curate texts that look at different periods in history and that are both Portugese and English and tutors picked up on this and mediated app usage around his own culture, language, and interests. One final dimension of Clare and Peter's tutoring sessions on iPads is her observation that Peter likes to speak around apps - that is talk about what he has learned about history as he plays a game or app. This finding corresponds with other tutees who talked during app play. What this short excerpt of data reveals is not only the difference between apps that work on more of a participatory logic outlined in the next section, but also how digital literacy can be taught through an ideological model.

An educational literacy app therefore should develop more than tight framings and isolated skills, it should develop children's print literacy, moving them toward avid reading, writing craft, deep engagement with informational and literary texts, within the communities of readers and writers nurtured in school through familiar reading and writing workshops. Just as important, good educational apps should develop children's participatory literacies - the set of dispositions, knowledges, and abilities that digital users need to know in order to fully participate in online cultures that cross disciplinary boundaries. 


\section{Dimensions of Participatory Literacy Learning}

Building on Heins-Israelson's app maps that skillfully align literacy practices with appropriate app affordances, our hope is to encourage teachers to step outside of tighter framings and let digital and multimodal ideologies inform app choice and app teaching. The app world has exploded to such an extent, that it is impossible to leverage the power and possibilities of all these dimensions. The examples we have shared have given a glimpse of the participation gap that still exists between apps that skim the surface to drill on single skills and apps that delve deeply into inquiry and design.

The rubric and app maps are one way to track and display the depth of dimensions that apps enable. More dimensions lead to more complex learning so that robust and engaging apps like Minecraft allow learners to produce their own multimodal content and follow their passions through open-ended journeying in collaboration with multiple players and shared across networks. But, it is important to point out that apps do not necessarily need all these dimensions to have value. Learning is idiosyncratic and individual and should be ideological, and as with all literacies, a learner's purpose for using the app is of primary importance. Sometimes children just want to play, and the goal is pleasure for its own sake, as in momentary distractions such as Candy Crush or in aesthetic explorations such as Color Uncovered. Each dimension can be important in its own right, or, apps can merge all of the dimensions into one immersive world such as the Minecraft app. Design matters here and teachers should look for apps that combine dimensions purposefully to enhance learning potential, not simply to add or maximize more dimensions. For example, in pursuit of open-endedness, choose-your-ownadventure software erred in offering excessive choices that led to distracting and chaotic pathways rather than engaged learning (Hirsh-Pasek et al., 2015).

One way forward is to resist the urge to fall back on comfortable beliefs and convictions and look at what is actually happening with apps and the constrained ways of knowing that they invite. There is an autonomous model of literacy (Street, 1984, 1995) at work here that still circulates $20^{\text {th }}$ century assumptions about what learners should know and who they should become. In his writings, Street describes the autonomous model as the ways in which people use cognitive and linguistic skills and processes separate or autonomous from social contexts in simple terms, a person has or does not have a universalized set of skills. Cognitive and linguistic practices do not work this way, they are shaped by contexts and backgrounds and they can shift as people enter and exit different contexts. We want to stress that this is not an issue of print versus digital, rather it is more an issue of expanding the conversation to address contemporary realities. Rather than rating apps based on outmoded standards, layperson's impressions, or developmental measures, we can focus on dimensions that lead to deeper inquiry and more immersive learning to consider how an app makes learners feel and think and share and connect. Moving from a top-down evaluation to a bottom-up performance-based observation is an important first step. Here, we've provided a roadmap to help ensure that these beginning steps keep pace with the digital literacies and technologies on a shifting textual landscape. 


\section{Pause and Ponder}

1. What kinds of literacy practices are enabled or encouraged in the app your students use most? Is this app simply a printed page on a glass screen? Is this app actually a digital worksheet? Are children's literacy practices with this app much different than those used reading a print book? Or does it inspire children to go further? Is this app truly engaging? Would children choose to play with it if they weren't at school?

2. Through their app play, are children developing mastery over a simplified literacy skills or concepts? Are collaborating with other children or working alone? Are children's online interactions limited by pre-determined menu options, secure chats, and other isolating safeguards? Or are they developing participatory literacies such as producing original content and developing independence in the complex digital literacy practices needed to fully participate in a connected world? Are creative opportunities to explore, produce, and participate available to all children in equitable ways? If not, what are the effects on of these differences on children's development of participatory literacies?

3. Have you structured app use in your classroom to support collaboration, production, openended choice, and connection? Are there school structures such as solitary work assignments or firewall barriers that need to be changed to encourage children to play together and collaborate, to create their own original content, or to connect with family and friends on digital networks?

\section{Take Action!}

1. Observe and consider the kinds of literacy practices that are enabled by the apps your students use: practicing skills, reading e-books, animating videos, or designing interactive worlds.

2. Analyze how well the app provides opportunities for developing the six dimensions of participatory literacies on the rubric.

3. When selecting new apps, look for high potential for creative content production, multimodal interaction, open-ended exploration, collaboration, and networked sharing. Make sure that the apps you choose actually engage children and inspire further inquiry and ask yourself: Do all children have equitable opportunities to explore and create? Tight spaces are an apps' ideological effects.

4. Consider how your classroom structures could be altered to further support collaboration, production, connectivity, and other dimensions of participatory literacies. 


\section{More to Explore}

1. Using Apps to Put Creative Tools into Young Hands. Blog post by Stuart Dredge on the Joan Ganz Cooney website. July 7, 2015.

http://www.joanganzcooneycenter.org/2015/07/07/using-apps-to-put-creative-tools-intoyoung-hands/

2. 3 Truths and a Fib about Language and Literacy Apps for Children. Blog post by Lisa Guernsey, Michael Levine, and Sarah Vaala. October 20, 2015.

https://www.edsurge.com/news/2015-10-20-3-truths-and-a-fib-about-language-andliteracy-apps-for-

children?utm_content=buffer51f4e\&utm_medium=social\&utm_source=twitter.com\&utm_ campaign=buffer

3. Family Time with Apps-an ibook guidebook for selecting and using apps with young children http://itunes.com/familytimewithapps

4. \#kinderchat-grassroots weekly twitterchat for early childhood educators with a focus on supporting teachers interested in creative teaching and learning with technology http://www.kinderchat.org/

5. Henry Jenkins on Participatory Culture YouTube video that explains how technologies support and expect new ways of using literacy to participate in digital cultures https://www.youtube.com/watch?v=1gPm-c1wRsQ

\section{References}

Abrams, S. S. (2015). Integrating virtual and traditional learning in 6-12 classrooms: A layered literacies approach to multimodal meaning making. New York, NY: Routledge.

Apple Inc. (2015). iTunes preview: Sound uncovered by Exploratorium. Retrieved from https://itunes.apple.com/ca/app/sound-uncovered/id598835017?mt=8

Beavis, C. (2013). Multiliteracies in the wild: Learning from computer games. In Merchant, G., Gillen, J., Marsh, J., \& Davies, J. (Eds.), Virtual literacies. London, UK: Routledge.

Black, R. W., Korobkova, K., \& Epler, A. (2013). Barbie Girls and Xtractaurs: Discourse and identity in virtual worlds for young children. Journal of Early Childhood Literacy, 14(2), 265-285.

Bloome, D. \& Green, J. (2015). The social and linguistic turns in studying language and literacy. In J. Rowsell \& K. Pahl's The Routledge Handbook of Literacy Studies. London: Routledge.

Buchholz, B. A. (2015). Drama as serious (and not so serious) business: Critical play, generative conflicts, and moving bodies in a 1:1 classroom. Language Arts, 93(1), 7-24.

Buckingham, D. (2003). Media education: Literacy, learning, and contemporary culture. Cambridge, UK: Polity Press.

Burnett, C. \& Merchant, G. (2014). Points of view: Reconceptualizing literacies through an exploration of adult and child interactions in a virtual world. Journal of Research in Reading, 37(1), 36-50.

Children's Technology Review. (2015). Retrieved from http://childrenstech.com

Chiong, C. (2011). A matter of app: A children's educational app review blog. Retrieved from http://childrensappreview.blogspot.ca 
Common Sense Media Inc. (2015). Our mission. Retrieved from https://www.commonsensemedia.org/about-us/our-mission\#about-us

Flewitt, R., Messer, D., \& Kucirkova, N. (2015). New directions for early literacy in a digital age: The iPad. Journal of Early Childhood Literacy, 15(3), 289-310.

Gee, J.P. (2003). What video games have to teach us about learning and literacy. New York, NY: Palgrave MacMillan.

Gee, J. P. (2005). Why video games are good for your soul: Pleasure and learning. Melbourne, AU: Common Ground.

Gee, J.P. (2007). Good video games and good learning. New York, NY: Peter Lang.

Gillette-Mallard, K. (2015, June 25). A new framework to identify educational apps. Retrieved from http://www.tapclickread.org/a-new-framework-to-identify-educational-apps/

Guernsey, L. \& Levine, M. (2014). Tap, click, read. Retrieved from http://www.tapclickread.org

Hirsh-Pasek, K., Zosh, J. M., Golinkoff, R. M., Gray, J. H., Robb, M. B., \& Kaufman, J. (2015). Putting education in "educational" apps: Lessons from the science of learning. Psychological Science in the Public Interest, 16(1), 3-34.

Heins-Israelson, M. (2015). The App Map: A tool for systematic evaluation of apps for early literacy learning. The Reading Teacher, 69(3), 339-349.

Jenkins, H., Purushotma, R., Clinton, K., Robison, A. J., and Weigel, M. (2006). Confronting the challenges of participatory culture: Media education for the 21st Century. Chicago, IL: The John D. and Catherine T. MacArthur Foundation.

Kress, G. (1997). Before writing: Rethinking the paths to literacy. New York, NY: Routledge Press.

Kress, G. (2004). Reading images: Multimodality, representation and the new media. Information Design Journal \& Document Design, 12(2), 110-119.

Kress, G. (2010). Multimodality: A social semiotic approach to contemporary communication. London, UK: Routledge.

Leander, K. M., \& Boldt, G. M. (2013). Rereading "A pedagogy of multiliteracies": Bodies, texts, and emergence. Journal of Literacy Research, 45(1), 22-46.

Ly, A. (2014, October 2). A snapshot of kids' language and literacy apps 2015. Retrieved from https://dev-edcentral.pantheon.io/whats-store-today-snapshot-kids-language-literacyapps-part-2/

Marsh, J. (2011). Young children's literacy practices in a virtual world: Establishing an online interaction order. Reading Research Quarterly, 46(2), 101-118.

Marsh, J. (2012). Children as knowledge brokers of playground games and rhymes in the new media age. Childhood, 19(4), 508- 522.

Rideout, V. J. (2011). Zero to eight: Children's media use in America 2011. San Francisco, CA: Common Sense Media.

Rideout, V. J. (2013). Zero to eight: Children's media use in America 2013. San Francisco, CA: Common Sense Media.

Rowe, D. W. (2010). Directions for studying early literacy as social practice. Language Arts, 88(2), 134-143.

Puentedura, R. (2010). SAMR and TPCK: Intro to advanced practice. Retrieved from hippasus.com/resources/sweden2010/SMAR_TPCK_IntroToAdvancedPractice.pdf. 
Rowsell, J., Maues, F., \& Colquhoun, C. (forthcoming). iPads and autodidacts: Capturing reading processes and practices on iPads. In Burnett, C., Merchant, G., Simpson, A., \& Walsh, M. (Eds.), Mobile literacies: The case of the iPad. New York, NY: Routledge.

Rowsell, J. \& Pahl, K. (Eds.). (2015). The Routledge handbook of literacy studies. London, UK: Routledge.

Shuler, C. (2010). iLearn: An analysis of the education category on Apple's app store. New York, NY: Joan Ganz Cooney Center.

Shuler, C. (2012). iLearn II: An analysis of the education category on Apple's app store. New York, NY: Joan Ganz Cooney Center.

Street, B. (1984). Literacy in theory and practice. Cambridge, UK: Cambridge University Press.

Street, B.V. (1995). Social literacies: Critical approaches to literacy in development, ethnography, and education. Harlow, UK: Pearson Education.

Thiel, J. (2015). 'Bumblebee's in trouble!' Embodied literacies during imaginative superhero play. Language Arts, 93(1), 38-49.

Wohlwend, K. E. (2012). A new spin on miscue analysis: Using spider charts to web reading processes. Language Arts, 90(2), 110-118.

Wohlwend, K. E. (2015). One screen, many fingers: Young children's collaborative literacy play with digital puppetry apps and touchscreen technologies. Digital media and literacies special issue. Theory Into Practice, 54, 154-162.

Wohlwend, K. E., Vander Zanden, S., Husbye, N. E., \& Kuby, C. R. (2011). Navigating discourses in place in the world of Webkinz. Journal of Early Childhood Literacy, 11(2), 141-163.

Acknowledgements: We would like to acknowledge funding from the Social Justice Research Institute through a Community Engagement Grant for the twenty-first century tutoring research. As well, we would like to acknowledge tutors, tutees, and families for their participation in the research and Dr. Fernando Maues and Chrystal Colquhoun as researchers on the project. 